\title{
Karin Schneider, Eva Maria Werner, Europa in Wien. Who is who beim Wiener Kongress 1814/15
}

Wien, Köln, Weimar : Böhlau, 2015, 385 p., 34,99€.

\section{Sébastien Schick}

\section{CpenEdition}

\section{Journals}

Édition électronique

URL : http://journals.openedition.org/ifha/8534

DOI : 10.4000/ifha.8534

ISSN : 2198-8943

Éditeur

IFRA - Institut franco-allemand (sciences historiques et sociales)

Référence électronique

Sébastien Schick, « Karin Schneider, Eva Maria Werner, Europa in Wien. Who is who beim Wiener Kongress 1814/15 », Revue de I'IFHA [En ligne], Date de recension, mis en ligne le 01 janvier 2016, consulté le 22 septembre 2020. URL : http://journals.openedition.org/ifha/8534 ; DOI : https://doi.org/ 10.4000/ifha.8534

Ce document a été généré automatiquement le 22 septembre 2020.

(CIFHA 


\title{
Karin Schneider, Eva Maria Werner, Europa in Wien. Who is who beim Wiener Kongress 1814/15
}

Wien, Köln, Weimar : Böhlau, 2015, 385 p., 34,99€.

\author{
Sébastien Schick
}

1 Le bicentenaire du congrès de Vienne a donné lieu à différents colloques et publications qui ont permis de renouveler en partie notre compréhension de ce moment fondamental de l'histoire diplomatique et politique européenne. Dans ce contexte, Karin Schneider et Eva Maria Werner ont choisi de centrer leur ouvrage sur les acteurs, et de considérer ainsi le congrès comme un événement social plutôt que politique. Il s'agit pour les deux historiennes d'Innsbruck d'identifier les négociateurs et les délégations officielles qui rejoignirent pour quelques mois les bords du Danube, mais également - et c'est là ce qui fait l'intérêt de la démarche - l'ensemble des personnalités politiques, des princes et des ministres, des «lobbyistes", des marchands, des aventuriers, ou des personnalités artistiques, qui se retrouvèrent pour l'occasion. La ville devint alors, pour quelques mois, le centre social de l'Europe, et c'est à la reconstruction de cette centralité, à l'analyse des lieux de rencontre et d'échange, de discussions formelles et informelles, que les deux historiennes s'attèlent.

2 La majeure partie de l'ouvrage (p. 100-326) est constituée de 248 notices, qui sont consacrées à des personnalités présentes à Vienne entre septembre 1814 et juin 1815. Sans aucun doute, ces courtes biographies représentent un outil de travail tout à fait utile et pratique pour l'historien. Toutefois, le projet ne va pas sans poser problème d'un point de vue méthodologique, à commencer, comme le soulignent les deux auteurs, par le choix des individus présentés (p. 9): si la liste des négociateurs officiellement accrédités et de leurs accompagnateurs, des princes et des personnes siégeant au sein des différentes commissions du congrès représente un élément objectif, comment décider, au sein de l'ensemble bigarré qui s'est réuni en marge du congrès, sur qui porter son attention? Dès lors que les deux auteurs ne font que soulever le problème, sans justifier leur choix d'un point de vue méthodologique, les 
pages qui suivent satisfont souvent la curiosité (Beethoven se trouvait par exemple à Vienne à cette époque, et il composa la cantate «Der glorreiche Augenblick» en l'honneur du congrès - p. 111), sans que l'on en sache davantage sur le statut du panel finalement présenté. On soupçonne alors que les « grands hommes » aient été privilégiés - même si des contre-exemples pourraient être cités -, à contre-courant, donc, de l'historiographie récente, et quand bien même les informations les concernant sont accessibles par ailleurs ; comment comprendre, sinon, le choix présenté comme évident en introduction, de porter davantage son attention sur les "acteurs centraux " (die zentralen Akteure) du congrès, tel Metternich, plutôt que sur le représentant de la principauté de Schwarzburg-Rudolstadt (p. 9)?

3 Trois chapitres (p. 11-99) précèdent cette partie centrale, et offrent des précisions utiles sur les modalités et le décor des rencontres. Le premier présente les cadres formels de la négociation, ce qui permet de rappeler, par exemple, que les discussions n'eurent jamais lieu que de manière bilatérale ou en commissions et comités spécialisés, et qu'il ne peut, de ce point de vue, être question à proprement parler d'« un congrès » (p. 17). Le deuxième s'intéresse aux lieux qui se trouvèrent au cœur des négociations, ce qui permet d'entrevoir l'impact du congrès sur l'espace urbain, et de deviner quels furent les principaux lieux de sociabilité entre les différentes personnalités présentées dans la partie biographique : on y découvre à la fois les lieux des discussions officielles (la Chancellerie d'État) et ceux qui furent le théâtre des échanges plus informels, que ce soient les lieux d'hébergement - les palais aristocratiques, la Hofburg, un ensemble d'auberges ou d'appartements, selon le statut, le rang, et les moyens des individus -, de divertissement comme les bals et les théâtres, ou les lieux de promenade. Le dernier chapitre, dont le statut, au sein du projet d'ensemble, n'est pas parfaitement clair, traite de la dimension politique du congrès, considérée du point de vue de la communication politique et de la circulation de l'information. Les deux auteurs redonnent alors toute leur importance politique aux « amusements » et festivités qui se déroulèrent en marge du congrès - par exemple la grande course de trâ̂neaux du 22 janvier 1815 -, avant d'analyser les différentes sources d'information (les journaux surtout, autrichiens mais aussi étrangers, malgré la censure) dont disposaient les acteurs du congrès.

4 Ainsi, l'ouvrage de Karin Schneider et d'Eva Maria Werner offre à la fois une bonne introduction sur certains aspects du congrès, et un outil de travail utile sur les dimensions sociales de cet événement. Toutefois, écrire une véritable histoire sociale de cette rencontre diplomatique et politique - mais était-ce là véritablement l'objectif ? - aurait nécessité, tant du point de vue des sources que de l'outillage méthodologique (la prosopographie plutôt que la juxtaposition de notices biographiques), un travail bien plus ambitieux.

5 Vous trouverez la table des matières ici : http://d-nb.info/1050726405/04. 
INDEX

Index chronologique : Période moderne, Période contemporaine

Thèmes : Histoire des États et des pouvoirs, Manuels/Ouvrages généraux/Outils de travail

\section{AUTEUR}

\section{SÉBASTIEN SCHICK}

Université Paris 1 Panthéon-Sorbonne - IHMC 